\title{
Rancang Bangun Virtual Reality Psikologi Positif
}

\author{
Erika Rachma Aprilia ${ }^{1)}$, Mardawia M. Parenreng') \\ 1),2) Teknik Elektro Politeknik Negeri Ujung Pandang \\ erikarachma60@gmail.com ${ }^{1)}$,mmparenreng@gmail.com ${ }^{2)}$
}

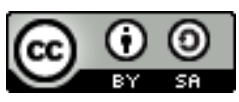

\begin{abstract}
Mahasiswa perlu memiliki jiwa yang baik untuk menghadapi setiap persoalan sehari-hari. Tetapi, tidak bisa dipungkiri bahwa mahasiswa memiliki banyak beban yang dihadapinya terutama mahasiswa yang berada pada tahun terakhir. Beberapa kasus bunuh diri terjadi akibat mahasiswa yang stress dengan tugas. Aplikasi virtual reality psikologi positif muncul untuk menghadapi persoalan tersebut sebagai media edukasi penerapan psikologi positif. Penelitian ini menggunakan metode pengembangan multimedia meliputi tahap studi literatur, perancangan aplikasi, prototipe aplikasi berupa pembuatan objek $3 D$ dan interface aplikasi, dan tahap pengujian. Aplikasi ini dibuat dengan menggunakan Unity 3D dan GoogleCarboard sebagai Software Development Kit (SDK). Aplikasi berjalan pada system operasi android dan dihubungkan dengan media berupa $V R$ box serta joystick controller. Adapun hasil pengujian terhadap aplikasi yang telah dibangun menunjukkan bahwa seluruh perancangan aplikasi virtual reality Psikologi Positif telah terpenuhi sesuai dengan indikator pengujian.
\end{abstract}

Keywords: Mahasiswa, Virtual Reality, Psikologi Positif, Unity 3D

\section{PENDAHULUAN}

Mahasiswa perlu memiliki jiwa yang baik untuk menghadapi setiap persoalan sehari-hari. Tetapi, tidak bisa dipungkiri bahwa mahasiswa memiliki banyak beban yang dihadapinya terutama mahasiswa yang berada pada tahun terakhir. Beberapa kasus bunuh diri terjadi akibat mahasiswa yang stress dengan tugas akhirnya.

Menghadapi persoalan di atas, salah satu pencegahan yang paling dasar untuk mengatasi stress adalah psikologi positif. Pendekatan psikologi positif merupakan salah satu tindakan preventif dalam menghadapi stres dan mencegah ke penyakit mental yang lebih berat juga bunuh diri. Tujuannya adalah mengidentifikasi dan meningkatkan kekuatan dan kebajikan manusia yang membuatnya dapat hidup dengan layak dan memungkinkan individu dan masyarakat untuk berkembang (dalam Aulia, 2015)

Aplikasi virtual reality psikologi positif muncul untuk menghadapi persoalan tersebut sebagai media edukasi penerapan psikologi positif.

\section{KAJIAN LITERATUR}

Penelitian dalam bidang psikologi menggunakan VR sekarang ini sudah banyak.
Seperti penggunaan VR untuk pasien yang mengalami gangguan rasa sakit. Penelitian yang dilakukan oleh Sridevi (2012) ini membuat dunia virtual salah satunya dunia salju. Pasien menggunakan VR dengan beberapa sesi dan terbukti mengurangi gangguan rasa sakit pada sebagian besar pasien. Tetapi dalam penelitian ini, pengguna harus diinformasikan secara baik tentang kegunaan VR ini agar tidak gugup saat menggunakannya. Hal itu akan berpengaruh pada kegunaan VR untuk mengurangi rasa sakit pasien.

Selanjutnya, ada Adyo (2017) yang menggunakan VR untuk terapi akrofobia (fobia ketinggian). Dalam penelitian ini, terdapat beberapa tahap yang harus dilalui oleh pasien secara berkala untuk mengurangi kecemasan berlebihan terhadap ketinggian. Namun, penelitian ini menangani pengurangan rasa sakit dan gangguan kecemasan yang lebih lanjut. Bukan sebagai tindakan preventif.

(1)Psikologi positif sebagai studi ilmiah tentang fungsi manusia yang positif dan berkembang pada beberapa tingkat yang mencakup biologi, personal, relasional, kelembagaan, budaya, dan dimensi global hidup. Tujuannya adalah mengidentifikasi dan meningkatkan kekuatan dan kebajikan manusia yang membuatnya dapat hidup dengan layak dan memungkinkan individu dan masyarakat untuk berkembang. (2)Virtual Reality adalah lingkungan tiruan yang diciptakan dengan 
perangkat keras dan perangkat lunak komputer dan disajikan kepada pemakai sehingga pemakai tersebut merasakan seperti dalam lingkungan nyata.(3)Untuk membuat sebuah game, maka dibutuhkan game engine yaitu Unity 3D yang merupakan sebuah software (perangkat lunak) yang dirancang untuk dapat menciptakan atau mengembangkan video Game. (4)Untuk modeling, Blender 3D digunakan untuk modeling, texturing, lighting animating dan video post processing 3 dimensi.

\section{METODE PENELITIAN}

Perancangan aplikasi yang dibangun berbasis android. Dalam penerapannya akan dibuat sebuah objek 3D yang akan menampilkan pemandangan pegunungan dan pantai. Lalu setelah objek 3D dibuat maka pengguna akan membutuhkan perangkat tambahan yaitu kacamata $V R$ untuk membantu pengguna agar bisa masuk dan berinteraksi secara langsung dalam dunia 3D. Berikut tahapan perancangan aplikasi VR yang ditunjukkan oleh gambar 1 dibawah ini.

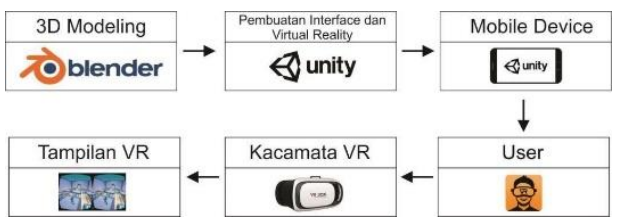

Gambar 1. Rancangan Aplikasi

\section{Use Case Diagram}

Use Case Diagram adalah gambaran graphical dari pengguna atau digunakan untuk menggambarkan sistem dari sudut pandang pengguna (user). Sehingga pembuatan use case diagram dititikberatkan pada fungsional yang ada pada sistem, bukan berdasarkan urutan kejadian. Berikut ini adalah use case diagram berbasis mobile dari aplikasi VR Psikologi Positif:

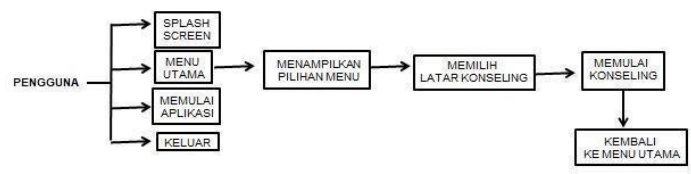

Gambar 2. Use Case Diagram
Perancangan sistem harus memperhatikan sasaran nantinya menjadi pengguna aplikasi ini, yaitu mahasiswa yang sebagian besar tidak familiar dengan teknologi VR. Oleh karena itu, perancangan sistem harus mudah digunakan oleh pengguna. Gambar 3.3 menunjukkan diagram use case untuk alur kerja aplikasi.

\section{Diagram Activity}

Activity diagram penggunaan aplikasi menggambarkan alur aktivitas yang terjadi dalam aplikasi pengenalan kosa kata bahasa inggris. Activity diagram menu ini menjelaskan saat user menggunakan menumenu utama yang terdapat pada aplikasi ini.

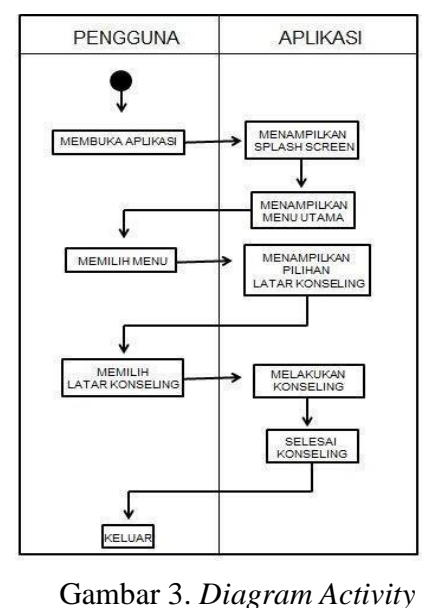

Pertama, pengguna akan membuka aplikasi, lalu akan diarahkan ke halaman utama akan ditampilkan dan masuk ke menu utama. Menu utama akan mengarahkan pengguna untuk mulai melakukan konseling. Kemudian pengguna akan melewati scene prolog agar pengguna bisa masuk ke dalam keadaan rileks. Prolog akan berisi tentang ajakan untuk menikmati pemandangan sekitar, perintah untuk mengatur napas, dan sugesti untuk bisa masuk ke dalam keadaan rileks. Setelah itu, pengguna bisa memulai konseling. Sebelum memulai konseling, pengguna akan masuk ke menu pemilihan latar konseling. Terdapat dua pilihan latar yaitu pantai dan pegunungan. Selanjutnya, pengguna akan melakukan konseling dengan topik "Takut mengikuti ujian sidang”. Setelah pengguna memilih, maka akan dilakukan dialog untuk mengidentifikasi masalah secara dengan menyediakan pilihan beberapa dialog. Lalu akan ada pertanyaan kepada pengguna tentang langkah nyata dalam menghadapi permasalahan yang telah 
diidentifikasi juga penerapan psikologi positif akan dilakukan dengan meningkatkan kepercayaan diri pengguna. Terakhir, ada pertanyaan untuk evaluasi apa yang pengguna rasakan setelah melakukan percakapan.

\section{HASIL DAN PEMBAHASAN}

Hasil tampilan antarmuka pada aplikasi dapat dilihat sebagai berikut:

\section{Splash Screen}

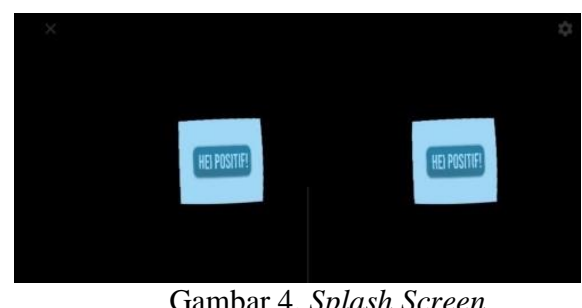

Gambar 4. Splash Screen

Pada gambar 4 menampilkan splashscreen atau tampilan awal dari aplikasi Konseling VR. Pada saat aplikasi dijalankan maka akan diawali dengan tampilan splash screen. Tampilan splash screen ini dibuat untuk menunjukkan identitas dari aplikasi.

\section{Interface Menu Utama Aplikasi}

Tampilan utama aplikasi ini merupakan tampilan aplikasi yang sudah siap digunakan.

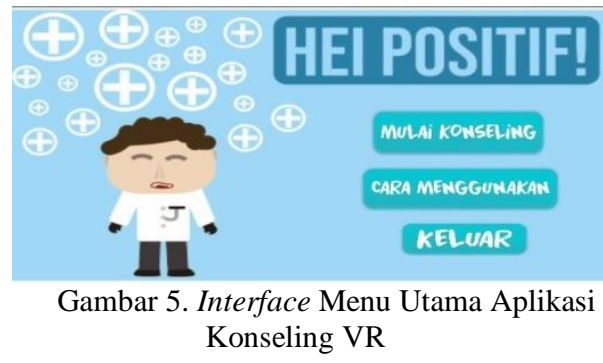

Pada gambar 5 menampilkan menu utama aplikasi Konseling VR terdapat 3 tombol yang dapat dipilih oleh berupa tombol untuk mengarahkan pengguna ke menu selanjutnya seperti memulai konseling, cara menggunakan untuk panduan cara menggunakan konseling VR, dan tombol keluar dari aplikasi.

\section{Interface Menu Prolog}

Tampilan ini adalah scene prolog di pegunungan maupun pantai sebelum masuk ke konseling

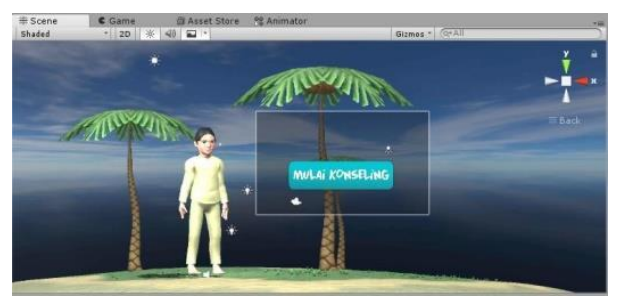

Gambar 6. Tampilan Scene Prolog Pegunungan

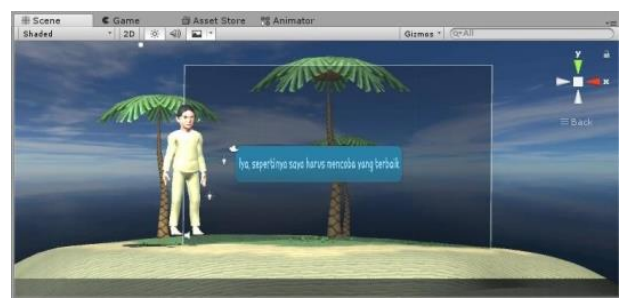

Gambar 7. Tampilan Scene Prolog Pantai

Gambar 6 dan 7 menunjukkan isi dari scene prolog. Dalam scene ini pengguna disarankan untuk melihat pemandangan sekitar melalui audio karakter. Dalam scene ini juga terdapat audio suara angin di pegunungan dan suara ombak di latar pantai. Selain itu, karakter akan memberi perintah untuk mengatur napas agar pengguna bisa masuk ke dalam keadaan rileks. Setelah itu, pengguna bisa memulai konseling dengan menekan tombol "Mulai konseling".

\section{Tampilan Scene Tahap Akhir Konseling}

Tampilan ini adalah scene prolog di pegunungan maupun pantai sebelum masuk ke konseling.

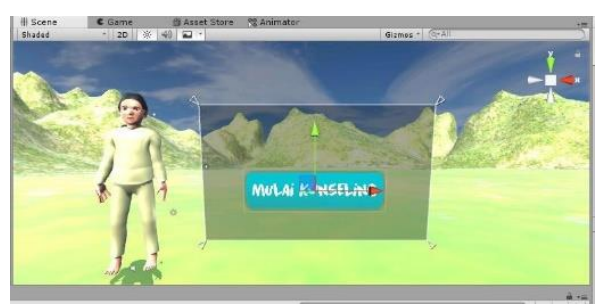

Gambar 8. Tampilan Scene Tahap Akhir Konseling Latar Pegunungan 


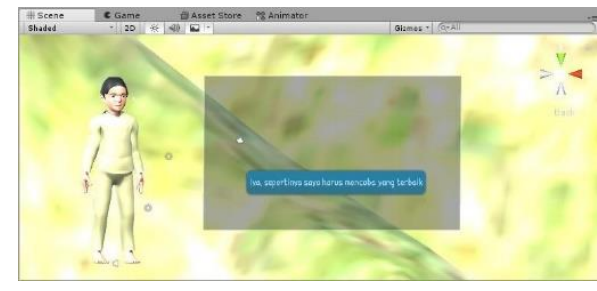

Gambar 9. Tampilan Scene Tahap Akhir Konseling Latar Pantai

Gambar 8 dan 9 menampilkan scene tahap akhir konseling virtual. Dalam scene ini adalah tahapan mengambil tindakan yang diarahkan oleh konselor. Dalam scene selanjutnya, akan tersedia dua tombol yaitu tombol ketika pengguna sudah mengetahui langkah nyata yang akan dilakukan dan ketika pengguna masih bingung dengan langkah yang akan diambil selanjutnya. Setelah melalui scene itu, maka disediakan tombol langkah nyata yang akan dilakukan.

\section{Pembahasan}

Pengujian ini berupa pengujian fungsional aplikasi. Pengujian dilakukan pada saat sistem aplikasi mulai dijalankan. Pengujian fungsional aplikasi akan menguji fungsifungsi dari Aplikasi Konseling VR apakah sudah terhubung dengan Controller. Hasil dari pengujian dapat dilihat pada Gambar 10.

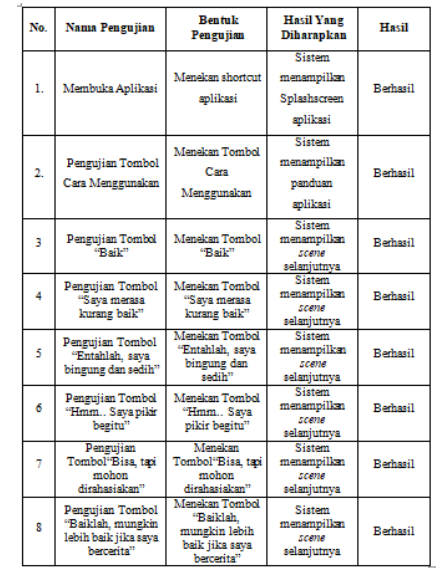

Gambar 10. Tabel Pengujian Fungsional Aplikasi

\section{Analisis Hasil Pengujian Aplikasi}

Berdasarkan hasil pengujian pada Gambar 10 di atas dapat dilihat bahwa fungsi semua menu pada aplikasi konseling virtual berjalan dengan baik, karena setiap menu yang dipilih oleh pengguna sudah saling terhubung.
2. Analisa Hasil Pengujian Kuisioner Pengujian kuisioner dilakukan secara objektif terhadap aplikasi yang telah berhasil dirancang. Pengujian dilakukan oleh 10 responden.Dimana responden mengoperasikan aplikasi dan memberikan penilaian atau tanggapan terhadap beberapa pernyataan seputar aplikasi pada gambar 11 daftar pertanyaan.

\begin{tabular}{|c|l|}
\hline No. & \multicolumn{1}{|c|}{ Pertanyaan } \\
\hline 1. & Bagaimana pendapat Anda mengenai tampilan aplikasi ini? \\
\hline 2. & Sebagai pengguna, apakah aplikasi ini mudah digunakan? \\
\hline 3. & $\begin{array}{l}\text { Bagaimana pendapat Anda mengenai skenario konseling dalam aplikasi } \\
\text { ini? Apakah mewakili perma salahanyang biasa ditemui mahasiswa akhir? }\end{array}$ \\
\hline 4. & $\begin{array}{l}\text { Menurut Anda, apakahkonseling virtual reality ini memb antumenghadapi } \\
\text { permasalahan Anda? }\end{array}$ \\
\hline 5. & ApakahAnda puas dengan aplikasi ini? \\
\hline
\end{tabular}

Gambar 11. Pertanyaan Pengujian Fungsional

Berikut adalah grafik hasil penilaian terhadap pertanyaan pada tabel 4.2 yang dilakukan

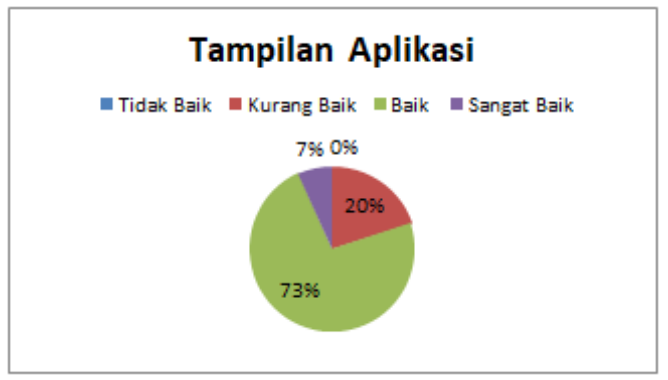

Gambar 12. Grafik Penilaian terhadap Pertanyaan 1

Gambar 12 respon dari responden sebagian besar $(73 \%)$ menunjukkan bahwa tampilan aplikasi ini sudah baik. (20\%) kurang baik, dan $(7 \%)$ sangat baik.

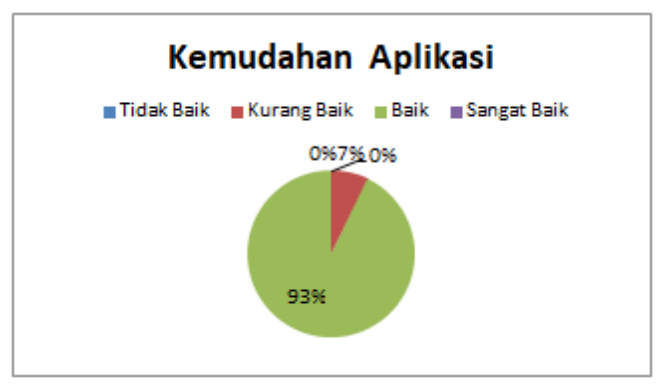

Gambar 13. Grafik Penilaian terhadap Pertanyaan 2 
Gambar 13 respon dari responden sebagian besar $(93 \%)$ menunjukkan bahwa aplikasi ini mudah digunakan dan (7\%) kurang baik.

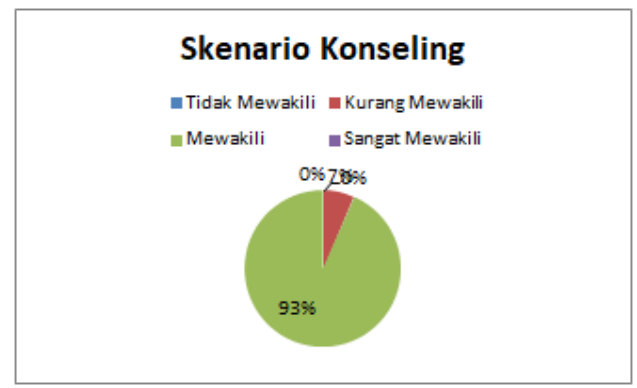

Gambar 14. Grafik Penilaian terhadap Pertanyaan 3

Gambar 14 respon dari responden sebagian besar (93\%) menunjukkan bahwa skenario konseling ini mewakili permasalahan yang biasa ditemui mahasiswa akhir dan (7\%) yang memilih kurang mewakili.

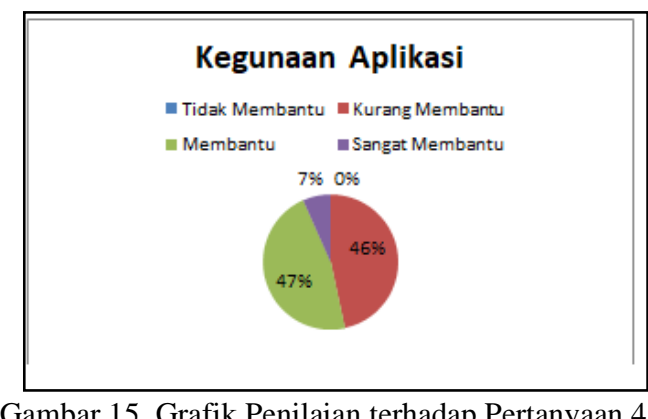

Gambar 4.18 respon dari responden sebagian besar (47\%) menunjukkan aplikasi ini membantu permasalahan responden, $(46 \%)$ kurang membantu, dan (7\%) sangat membantu.

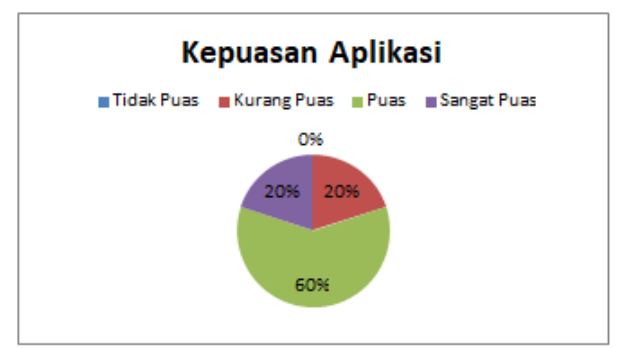

Gambar 16. Grafik Penilaian terhadap Pertanyaan 5

Gambar 4.19 respon dari responden sebagian besar $(60 \%)$ menunjukkan responden puas dengan pembuatan aplikasi ini, (20\%) tidak puas, dan (20\%) kurang puas.

\section{KESIMPULAN}

Hasil penelitian Rancang Bangun Virtual Reality Psikologi Positif sebagai konseling virtual dapat disimpulkan bahwa perancangan aplikasi berjalan sesuai dengan yang dirancang oleh penulis yaitu pembuatan karakter 3D untuk karakter konselor dan pembuatan fitur aplikasi dengan menggunakan teknologi Virtual Reality. Berdasarkan hasil pengujian dengan metode black box testing menunjukkan bahwa perancangan aplikasi Virtual Reality Psikologi Positif telah terpenuhi sesuai dengan indikator pengujian.Aplikasi ini juga dinilai baik menurut hasil pengujian kusioner.

\section{UCAPAN TERIMA KASIH}

Pada kesempatan ini penulis mengucapkan terima kasih kepada semua pihak yang telah memberi dorongan positif kepada penulis baik secara langsung maupun tidak langsung. Penulis berharap semoga penelitian ini dapat berguna, bermanfaat, dan dijadikan referensi bagi yang tertarik mengembangkan penelitian ini.

\section{REFERENSI}

[1] Aulia, Farah. 2015. Aplikasi Positif dalam Konteks Sekolah. Seminar Psikologi dan Kemanusiaan. Universitas Gadjah Mada.

[2]Hasan, Reski. 2017. Rancang Bangun Aplikasi Virtual Reality Pengenalan Dan Teknik Dasar Bermain Bola Basket Berbasis Android. Tugas akhir Politeknik Negeri Ujung Pandang: tidak terbit

[3] S, Sridevi. 2012. Immersive VR for Pain Distraction Methodologies and Barriers. India. IEEE- Fourth International Conference on Advanced Computing, ICoAC 2012 MIT, Anna University, Chennai. December 13-15, 2012

[4] Srivastava K, Das RC, Chaudhury S. 2014. VR applications in mental health: Challenges and perspectives. Ind Psychiatry $\mathbf{J}$ 2014;23:83-5. 